\title{
Demographic characteristics and health behaviours of consenters to medical examination. Results from the Welsh Heart Health Survey
}

\author{
Elaine Pullen, Don Nutbeam, Laurence Moore
}

\begin{abstract}
Study objective-The aim was to compare the demographic characteristics and health related behaviours of people who consented to a medical examination as part of a population survey with those who did not.

Study design-The study formed part of the (1985) Welsh Heart Health Survey, which comprised a three stage design involving household interview, self completion questionnaire, and medical examination. Subjects for medical examination were selected from responders to the questionnaire survey $(67 \%)$. Sixty six per cent of this group consented to medical examination $(n=11637)$. Odds ratio analysis techniques were used to compare consenters and non-consenters.
\end{abstract}

Measurements and main results-The analysis was based on self reported information available from previously completed questionnaires, and from personal interviews. The study supported the findings of previous research indicating that consenters to medical examination are more likely to be from non-manual social groups, to be aged $25-44$ years, to be educated beyond school age, and to be married. Individuals with healthy lifestyle characteristics (diet, physical activity) were overrepresented among consenters. The only exception to this finding was in relation to excessive alcohol consumption.

Conclusions-These findings emphasise the importance of maximising response rates in all forms of social research including surveys with a clinical component. They also have methodological and analytical implications for the Welsh Heart Health Survey.

f Epidemiol Community Health 1992; 46: 455-459

Department of Sociology, University of Warwick, Coventry, West Midlands CV4

7AL, United Kingdom

E Pullen

Health Promotion

Authority for Wales,

Brunel House,

Fitzalan Road,

Cardiff, United

Kingdom

D Nutbeam

L Moore

Correspondence to:

Ms Pullen

Accepted for publication October 1991
Almost all forms of health behaviour research are dependent on the voluntary participation of their population. In practice, relatively few questionnaire surveys achieve response rates in excess of $90 \%,{ }^{1}$ and levels of participation in health surveys which require subjects to undergo physical medical examination tend to be somewhat lower. ${ }^{2-5}$ Participation or response rates of less than $100 \%$ present an important threat to the validity of data, and techniques to maximise participation rates are commonly employed. 6 These may include, for example, incentives for participation and reminders to non-responders.

In studies where the final response is less than $100 \%$, some effort has to be made to assess the nature and extent of bias that might have been introduced as a result. ${ }^{7}$ The lower the response rate, the more important such an assessment becomes. ${ }^{8}$ Assessing the effects of non-response is especially important in studies designed to measure change in a population over time. Different response rates between individual surveys, and over time, may influence the validity and usefulness of observations about change.

The size and composition of participating and non-participating groups can vary considerably between studies. The characteristics and attitudes of the population being encouraged to participate as well as what "participation" actually entails (eg, the measures and tests individuals are required to undergo) have been shown to affect participation. ${ }^{15}$ Thus, while much can be learned about the potential for bias from previous studies in related fields, it is important for study designs to incorporate some means of comparing participant and non-participant groups in order to expose and correct for potential bias, and thereby improve confidence in the validity of the data.

This paper reports one such study, conducted as part of the 1985 Welsh Heart Health Survey. Respondents to a self completion questionnaire survey who agreed to a medical examination are compared with those who refused such an examination. The purpose of this analysis is to identify the demographic and behavioural characteristics of consenters to medical examination and how they differ from those of non-consenters. The analysis is one of a range of studies which have been undertaken to test validity and maximise confidence in the quality of data from the Welsh Heart Health Surveys. Other reported studies have separately investigated the potential bias introduced as a result of non-response to the self completion questionnaire ${ }^{9}$; and have examined differences in self reported behaviour or health status, compared to objective or biochemical measures.

\section{THE WELSH HEART PROGRAMME}

The Welsh Heart Programme is a national (United Kingdom) demonstration project to promote good health among the three million population of Wales and is particularly directed towards reducing the risks of cardiovascular disease throughout the whole of the principality. Its major priorities include promoting non-smoking, healthy nutrition, regular exercise, stress management, health screening, and first aid for heart attacks. The long term aim of the programme is to develop and evaluate, as a pilot programme, a regional strategy that will contribute to a sustained reduction in coronary heart disease incidence, morbidity, and mortality in the general 
population of Wales, and in particular those under the age of 65 years.

Heartbeat Wales was established as a national demonstration project, and evaluation of the effectiveness of the intervention has been a central part of the programme. A full range of evaluation methods is being used, and like community based interventions elsewhere assessment of outcome has been undertaken using a quasi-experimental design with the intervention population in Wales (treatment) being compared with a similar, reference population in another part of the United Kingdom (control). ${ }^{10}$ Experience in Wales and in other countries has shown this design as having the best potential to demonstrate the success of programmes when combined with studies which help explain the process of achieving change among individuals and within networks in communities. $^{11}$

\section{Methods}

THE WELSH HEART HEALTH SURVEYS

To establish a baseline of information on the prevalence of risk factors for cardiovascular disease, the Welsh Heart Health Survey was planned and carried out during 1985-6. The survey comprised three stages involving a household (personal) interview, a self completion and postal return questionnaire, and a medical examination. Full details of the methodology and basic results are separately published, ${ }^{12-15}$ and only an outline description is given below.

A random sample of households was selected through a three stage cluster sampling procedure from the Welsh electoral register. Of the households with which contact with a resident was made, $93.5 \%$ completed a doorstep interview. This initial interview was conducted with an adult member of the household and enabled the collection of basic information on the age, sex, and social class of all household members, including those who subsequently failed to complete questionnaires. Once the interview was completed, a questionnaire was left for each household member aged 12 to 64 years. A total of 32366 questionnaires were placed, and $67 \% \quad(n=21627)$ were returned as usable following two reminders.

A separate follow up study of originally sampled subjects who did not return self completion questionnaires revealed no major differences in risk factor profile between those who did and those who did not complete questionnaires, except in the case of smoking, where a significantly higher proportion of current smokers was found among the non-responding group. This finding was not fully accounted for by social class differences in response. ${ }^{9}$

The third stage of the survey (the medical examination) was undertaken for the dual purpose of establishing a baseline of clinical risk factors for coronary heart disease (such as raised serum cholesterol or blood pressure) and for validating the information obtained through the self completion questionnaires (for example smoking status, height, and weight)

The clinical study population comprised a quota sample selected from a subsample of subjects responding to the main Heart Health Survey described above. Individuals' willingness to undergo the medical examination required by the clinical study was established from responses to a specific question at the end of the questionnaire:

"A proportion of all persons completing this question booklet will have the opportunity to be given a free medical examination. This will be at a clinic and at a time convenient to you and will consist of simple routine tests covering such aspects as: height, weight, blood pressure, pulse, heart rate, and a skin test. A small blood and urine sample may also be required and a heart recording and fitness test may be performed.

You will of course, receive the results of the examination, with most of the details available immediately on completion of the tests.

If you should be given the chance, would you be willing to have such an examination?"

The following analysis is concerned only with responses to this question, comparing those who consented to such an examination with those who did not. Subjects aged 12-17 years have been excluded from the analysis because information obtained from these respondents on smoking and alcohol use was generally found to be less reliable. Information on education and marital status is also distinctly different among this age group. Usable self completion questionnaires were returned by $1750318-64$ year olds, and $66 \%$ of these $(n=11637)$ consented to take part in the clinical survey. Further details of the clinical study itself are available elsewhere. ${ }^{1315}$ For the remainder of this paper, the term "respondent" is used to refer to all individuals who completed Heart Health Survey questionnaires. Those who agreed, at the end of this questionnaire, to undergo a subsequent medical examination are referred to as consenters, and those who refused as non-consenters.

\section{STATISTICAL METHODS}

The comparison of consenters and non-consenters to medical examination was conducted through odds ratio analysis, using the LOGLINEAR programme on SPSS-X. Odds ratio analysis was selected as the most appropriate means of examining the factors which influence the probability of a subject consenting (or otherwise) to medical examination. This enabled assessment of associations between various personal and behavioural characteristics and a willingness to consent. The odds ratios and their standard errors were corrected for clustering using the method described by Kish. ${ }^{16}$ This correction requires multiplication of the crude odds ratio by the square root of the design effect for responder status, obtained from the $f$ ratio (ANOVA) for health district.

\section{Results}

DEMOGRAPHIC CHARACTERISTICS

Information on a number of demographic variables was available from the survey questionnaire. 
Associations between consenting levels and sex, age, social class, marital status, and educational attainment are illustrated in table I. Where appropriate, these results have been controlled for age, sex, and social class.

Sex

After controlling for age, social class, marital status, and education, a small but significant difference was found in consenting levels among women and men, with men being more likely to consent than women.

Table I Associations between demographic variables and consent to examination

\begin{tabular}{|c|c|c|c|c|}
\hline $\begin{array}{l}\begin{array}{l}\text { Consenters' } \\
\text { characteristics }\end{array} \\
\end{array}$ & $\begin{array}{l}\text { Percentage } \\
\text { (number) of } \\
\text { consenters }\end{array}$ & $\begin{array}{l}\text { Odds } \\
\text { ratio }\end{array}$ & $\begin{array}{l}\text { Corrected } \\
\text { odds ratio }\end{array}$ & $\begin{array}{l}95 \% \\
\text { Confidence } \\
\text { interval }\end{array}$ \\
\hline $\begin{array}{l}\text { Sex } \\
\text { Male } \\
\text { Female }\end{array}$ & $\begin{array}{l}68 \cdot 2(5745) \\
64 \cdot 8(5892)\end{array}$ & $1 \cdot 17$ & $1 \cdot 14^{\star}$ & 1.05 to 1.23 \\
\hline $\begin{array}{l}\text { Age (years) } \\
18-24 \\
25-44 \\
45-64\end{array}$ & $\begin{array}{l}59 \cdot 5(1653) \\
71 \cdot 4(5634) \\
63 \cdot 6(4350)\end{array}$ & $\begin{array}{l}0.84 \\
1.43\end{array}$ & $\begin{array}{l}0.94 \text { NS } \\
1.36 t\end{array}$ & $\begin{array}{l}0.82 \text { to } 1.06 \\
1.24 \text { to } 1.48\end{array}$ \\
\hline $\begin{array}{l}\text { Social class } \\
\text { Economically inactive } \\
\text { Non-manual } \\
\text { Manual }\end{array}$ & $\begin{array}{l}59 \cdot 9(902) \\
69 \cdot 3(5233) \\
65 \cdot 2(5502)\end{array}$ & $\begin{array}{l}0.80 \\
1 \cdot 21\end{array}$ & $\begin{array}{l}0.94 \mathrm{NS} \\
1 \cdot 13^{\star}\end{array}$ & $\begin{array}{l}0.80 \text { to } 1.08 \\
1.03 \text { to } 1.23\end{array}$ \\
\hline $\begin{array}{l}\text { Marital status } \\
\text { Married } \\
\text { Widowed, single, } \\
\text { divorced }\end{array}$ & $\begin{array}{l}68 \cdot 7(8879) \\
60 \cdot 3(2758)\end{array}$ & $1 \cdot 20$ & $1.33 t$ & 1.19 to 1.46 \\
\hline $\begin{array}{l}\text { Education } \\
\text { Beyond secondary level } \\
\text { Secondary only }\end{array}$ & $\begin{array}{l}71 \cdot 5(4876) \\
63 \cdot 3(6761)\end{array}$ & $1 \cdot 21$ & $1.38 t$ & 1.26 to 1.50 \\
\hline
\end{tabular}

Table II Associations between health related behaviours/beliefs and consent to examination

\begin{tabular}{|c|c|c|c|c|}
\hline $\begin{array}{l}\text { Consenters' } \\
\text { characteristics }\end{array}$ & $\begin{array}{l}\text { Percentage } \\
\text { (number) of } \\
\text { consenters }\end{array}$ & $\begin{array}{l}\text { Odds } \\
\text { ratio }\end{array}$ & $\begin{array}{l}\text { Corrected } \\
\text { odds ratio }\end{array}$ & $\begin{array}{l}95 \% \\
\text { Confidence } \\
\text { interval }\end{array}$ \\
\hline $\begin{array}{l}\text { Smoking status } \\
\text { Smoker } \\
\text { Non-smoker }\end{array}$ & $\begin{array}{l}66 \cdot 6(4085) \\
66 \cdot 6(7508)\end{array}$ & $1 \cdot 0$ & $0.98 \mathrm{NS}$ & 0.90 to 1.06 \\
\hline $\begin{array}{l}\text { Alcohol consumptio } \\
\text { Sensible } \\
\text { Excess }\end{array}$ & $\begin{array}{l}66 \cdot 4(9731) \\
70.9(1522)\end{array}$ & $0 \cdot 81$ & $0.81 t$ & 0.70 to 0.92 \\
\hline $\begin{array}{l}\text { Exercise } \\
\text { Regular } \\
\text { Infrequent }\end{array}$ & $\begin{array}{l}70 \cdot 9(3919) \\
64 \cdot 8(7526)\end{array}$ & 1.33 & $1 \cdot 29 \ddagger$ & $1 \cdot 18$ to 1.40 \\
\hline $\begin{array}{l}\text { Body mass } \\
\text { Not overweight } \\
\text { Overweight }\end{array}$ & $\begin{array}{l}67 \cdot 9(6604) \\
65 \cdot 7(4717)\end{array}$ & $1 \cdot 10$ & $1.09 \mathrm{NS}$ & 1.00 to 1.18 \\
\hline $\begin{array}{l}\text { Wholemeal bread } \\
\text { Yes } \\
\text { No }\end{array}$ & $\begin{array}{l}70.9(3269) \\
64.9(8314)\end{array}$ & $1 \cdot 32$ & $1 \cdot 28 \neq$ & $1 \cdot 16$ to 1.39 \\
\hline $\begin{array}{l}\text { Polyunsaturated ma } \\
\text { Yes } \\
\text { No }\end{array}$ & $\begin{array}{l}69 \cdot 3(1734) \\
66 \cdot 1(9754)\end{array}$ & $1 \cdot 16$ & $1.08 \mathrm{NS}$ & 0.97 to 1.19 \\
\hline $\begin{array}{l}\text { Skimmed/semi-skim } \\
\text { Yes } \\
\text { No }\end{array}$ & $\begin{array}{l}70 \cdot 4(2004) \\
65 \cdot 8(8453)\end{array}$ & 1.23 & $1 \cdot 20^{\star}$ & 1.07 to 1.32 \\
\hline $\begin{array}{l}\text { Active member soci } \\
\text { Yes } \\
\text { No }\end{array}$ & $\begin{array}{l}\text { on } \\
69 \cdot 7(4958) \\
64 \cdot 4(6617)\end{array}$ & $1 \cdot 27$ & $1 \cdot 19 \pm$ & 1.09 to 1.28 \\
\hline $\begin{array}{l}\text { Actions reduce hear } \\
\text { Definitely } \\
\text { Might/will not }\end{array}$ & $\begin{array}{l}70 \cdot 2(6459) \\
62 \cdot 6(5145)\end{array}$ & 1.41 & $1 \cdot 32 \ddagger$ & 1.22 to 1.42 \\
\hline
\end{tabular}

Age

Respondents were subdivided into three age bands: 18-24 years, 25-44 years, and 45-64 years. In relation to consenting, no significant difference was found between the youngest (18-24 years) and oldest (45-64) age groups. However, comparison of 25-44 and 45-64 year olds revealed the former to be overrepresented among consenters to medical examination.

\section{Social class}

Three categories, "manual" (social classes IIIM, IV, and V), "non-manual" (social classes I, II, and IIINM), and "economically inactive" were used in the analysis of social class differences. ${ }^{17}$ Levels of consenting were found to be higher among manual respondents than among the economically inactive (a group which includes the chronically sick and disabled). A comparison of manual and non-manual respondents revealed the latter to be overrepresented among consenters to medical examination.

\section{Marital status}

Married respondents were found to be overrepresented among consenters compared with those who were single, widowed, divorced, or separated.

\section{Educational attainment}

The Heart Health Survey questionnaire asked respondents to indicate the highest level of education they had completed. Individuals who had completed a university degree, a diploma, or a professional technical qualification, or who were still in full time higher or further education, were more likely to consent to medical examination than those educated to secondary school level only or who had left school earlier.

\section{HEALTH RELATED BEHAVIOURS AND BELIEFS}

The survey questionnaire contained a number of questions on respondents' health related behaviours and beliefs. The present analysis compares consenting to medical examination to self reported smoking status, alcohol consumption, leisure time exercise, body mass index, and diet. These results, presented in table II, were controlled to account for the effects of the five main demographic variables which might influence the results, namely age, sex, social class, marital status, and education.

\section{Smoking status}

No significant differences were found between consenting levels for non-smokers (including exsmokers) and daily and occasional smokers.

\section{Alcohol consumption}

Respondents were divided into two groupsthose whose weekly alcohol consumption was within sensible limits as defined by Royal College of Physicians guidelines, ${ }^{18}$ and those whose consumption exceeded these limits: $>14$ standard units of alcohol weekly for women, and $>21$ standard units weekly for men. Those drinking within sensible limits were underrepresented among consenters compared to those drinking above these limits. 
Leisure time exercise

Data on leisure time exercise were compiled from information on the duration, intensity and frequency of leisure time activity. Those who were "moderately" or "strenuously" active for at least 20 min twice a week or more were compared with those exercising less often than this. Respondents who exercised regularly were better represented than those who were inactive.

Body mass index

The body mass index (BMI) of each respondent was calculated from their self reported weight (in $\mathrm{kg}$ ) divided by the square of their height (in $\mathrm{m}$ ). Males with a BMI in excess of 25 , and females in excess of 23 , were classified as overweight. ${ }^{19}$ Those who were within an "ideal" weight range were marginally better represented than those who were overweight.

\section{Diet}

Associations between consenting to examination and food choices were examined in relation to type of bread, milk, and fat for spreading on bread habitually used by respondents. These foods were selected because they were consumed in some form by the majority of respondents. (Of all respondents, $99 \%$ reported regularly eating bread; $92 \%$ used [dairy] milk and $96 \%$ spread butter, polyunsaturated margarine, ordinary margarine, or some other fat on their bread.)

When consenting is analysed in relation to respondents' consumption of these foods, it would appear that individuals regularly choosing the "healthier option" (higher fibre/lower fat) were more likely to consent to medical examination than those who did not. After controlling for demographic variables, the overrepresentation of respondents eating polyunsaturated margarine was not significant. Consumers of wholemeal bread and skimmed or semiskimmed milk remained overrepresented.

\section{Social participation}

The survey questionnaire contained a section on social activities. Questions regarding active membership of clubs, social organisations, churches, etc, were included. Individuals who were active members of social organisations were better represented than those who were not.

\section{Locus of control}

Part of the survey questionnaire focused upon perceived control over health status. ${ }^{20}$ Respondents were asked to indicate the extent to which they believed an individual's actions affected the chances of suffering a heart attack. Consenting to medical examination was found to be positively associated with increased confidence in the influence of personal action on individual health status.

\section{Discussion}

The Welsh Heart Health Survey was conducted during $1985 / 86$ to establish a baseline of data on health behaviours and coronary heart disease risks, against which future changes could be monitored. The three stage study was subject to a number of external threats to validity, including refusal to be interviewed, non-response to the self completion questionnaire, and refusal to consent to medical examination. This analysis is intended to identify the differences between consenters and non-consenters to the medical examination using information derived from the completed questionnaires forming the second stage of the study. This latter point is important in considering the results, as they concern only those people who agreed to participate in the study and had previously completed and returned a questionnaire $(93.5 \%$ and $68 \%$ respectively of the originally selected sample). No information has been sought on the $6.5 \%$ who refused to be interviewed. As previously indicated, a separate study of nonresponders to the questionnaire showed little difference, with the (important) exception of smoking, in terms of health behaviour and coronary heart disease risk factors between the $67 \%$ who responded and the $33 \%$ who did not. ${ }^{9}$ It is not possible to assume that the $33 \%$ nonresponders would behave the same in relation to consenting to a medical examination. However, in the study of non-responders, $72 \%$ consented to the medical examination which was part of that study, indicating that the non-responders may not differ greatly from the population considered in this report in relation to consenting to medical examinations.

The analysis presented in tables I and II reveals some potentially important differences in the demographic and behavioural characteristics of consenters and non-consenters to medical examination. Table I shows that consenters are more likely to be between 25 and 44 years old than in the 45-64 years age group; to be married; to be educated beyond secondary school level; and to come from non-manual households. In almost all cases, such results support those previous studies that have considered participation in medical examinations. ${ }^{21-24} \mathrm{With}$ these results, it is possible to use statistical techniques which help compensate for the small differences.

Much less attention has been given in published reports to the health related behaviours and beliefs of consenters and non-consenters. ${ }^{21} 2225$ The overall trend suggested by the data presented in table II is one of positive association between health enhancing behaviours, such as regular physical activity and good dietary choices, and consenting to medical examination. Regular social activity (club membership, etc) and positive beliefs about control over health status are similarly overrepresented among the consenting group.

However, table II also shows that respondents consuming alcohol in excess of sensible limits are overrepresented among consenters. This surprising result confounds the general trend which indicates that consenters to medical examination include a disproportionate number of individuals with positive health related behaviours. If one accepts the thesis that consenters to medical examination are an essentially health conscious group, this finding may indicate that health promotion messages regarding sensible limits for alcohol consumption are not reaching their targets as effectively as those concerning, for example, diet and exercise. 
Findings from this study have important implications for the Welsh Heart Health Survey, since they indicate that the questionnaire respondents who consent to medical examination do differ from non-consenters. Although none of the individual differences is large, especially when corrected for demographic variables, the data do highlight some dangers of relying heavily on "volunteers" as a population sample. While it is possible to employ statistical methods to control for differences between consenters and nonconsenters, solutions of this kind have limitations-particularly as the weighting would depend upon incomplete data from the questionnaire survey.

These findings informed our decision to follow the group who undertook medical examination as a cohort throughout the life of the programme. Contact has been maintained with the $74 \%$ $(n=1358)$ of this group still in Wales, and a subsample of $37 \%(n=605)$ of this remaining cohort underwent an interim medical examination in 1988. The whole cohort has been invited for re-examination in the 1990-91 follow up study, along with an independent, random population sample. This will provide comparative data, as well as establishing a second "baseline" for the next phase of the Heartbeat Wales programme 1990-95. This issue of differences between consenters and non-consenters will be examined again through the 1991 survey to consider whether differences have emerged between the two surveys which might affect the interpretation of results.

More generally, these findings may have implications for others who are planning or have undertaken health status surveys. In particular they emphasise the need to achieve the highest possible response rates, and point to some potential dangers in the recruitment of "volunteers" as a sample base in surveys intended to identify the population distribution of health behaviours and coronary heart disease risks.

Thanks to Dr Zoann Nugent for statistical advice, and to Professor David Murray and Christopher Smith for comments on an earlier draft of this paper.

1 Cartwright A. Health surveys in practice and potential: a critical review of their scope and methods. London: Kings Fund Publishing Office, 1983: 156.
2 Pirie PL, Elias WS, Wackman DB, et al. Characteristics of participants and non participants in a community cardiovascular disease risk factor screening: the Minnesota heart health program. Am 7 Prev Med 1986; 2: 20-5.

3 Walker M, Shaper AG, Cook DG. Non-participation and mortality in a prospective study of cardiovascular disease. $\mathcal{J}$ mortality in a prospective study of cardiovascular

4 Pill R, French J, Harding K, Stott N. Invitation to attend a health check in a general practice setting: comparison of attenders and non-attenders. $\mathcal{F} R$ Coll Gen Pract 1988; 38 53-6.

5 Anderson RM. Public attitudes to and experience of medical check-ups. Community Med 1983; 5: 11-20.

6 Campbell MJ, Waters WE. Does anonymity increase response rate in postal questionnaire surveys about sensitive subjects? A randomised trial. $f$ Epidemio Community Health 1990; 44: 75-6.

7 Kopec JA, Esdaile JM. Bias in case-control studies. A review. F Epidemiol Community Health 1990; 44: 179-86.

8 Moser CA, Kalton G. Survey methods in social investigation, 2nd ed. Aldershot, Hampshire: Gower Publishing Company, 1971.

9 Smith C, Nutbeam D. Assessing non-response bias: a case study from the 1985 Welsh Heart Health Survey. Health study from the 1985 We

10 Nutbeam D, Catford J. The Welsh Heart Programme evaluation strategy: progress, plans and possibilities. Health Promotion 1987; 2: 5-18.

11 Nutbeam D, Smith C, Catford J. Evaluation in health education. A review of progress, possibilities, and problems. I Epidemiol Community Health 1990; 44: 83-9.

12 Welsh Heart Programme Directorate. Welsh Heart Health Survey 1985: Protocol and questionnaire. Cardiff, 1985.

13 Welsh Heart Programme Directorate. Welsh Heart Health Survey 1985: Clinical manual. Cardiff, 1986.

14 Welsh Heart Programme Directorate. Pulse of Wales: Preliminary report of the Welsh Heart Health Survey 1985. Cardiff, 1986.

15 Welsh Heart Programme Directorate. Heart of Wales: Clinical results of the Welsh Heart Health Survey 1985. Cardiff, 1987.

16 Kish L. Survey sampling. New York: John Wiley and Sons, 1965.

17 Office of Population Censuses and Surveys. Classification of occupations. London: Government Statistical Service, HMSO, 1980

18 Royal College of Physicians. A great and growing evil: the medical consequences of alcohol abuse. London: Tavistock Publications, 1987.

19 Royal College of Physicians. Obesity: a report of the RCP. $f$ $R$ Coll Gen Pract 1988; 17: 5-66.

20 Wallston KA, Wallston BS, De Vellis RF. Development of the multi-dimensional health locus of control (MHLC) scale. Health Education Monographs 1978; 6: 160-70.

21 Criqui MH, Barrett-Connor E, Austin M. Differences between respondents and non-respondents in a populationbased cardiovascular disease study. Am ₹ Epidemiol 1978. 108: $367-72$.

22 Greenlick MR, Bailey JW, Wild J, Grover J. Characteristics of men most likely to respond to an invitation to be screened. Am f Public Health 1979; 69: 1011-5.

23 Sonne-Holm S, Soresen TIA, Jensen G, Schnohr P. Influence of fatness, intelligence, education and socioInfluence of fatness, intelligence, education and socioEpidemiol Community Health 1989; 43: 369-74.

24 Stromberg J, Dowd J, Glasunov I, et al. Predicting participation in a screening examination for ischaemic heart disease risk factors: experience from the Zegreb preliminary study. Soc Sci Med 1974; 8: 275-86.

25 Wilhelmsen L, Ljungberg S, Wedel H, Werko L. A comparison between participants and non-participants in a primary preventive trial. $f$ Chron Dis 1976; 29: 331-9. 